\title{
Copolymerization of ethylene with norbornene or 1-octene using supported ionic liquid systems
}

\author{
Wioletta Ochędzan-Siodłak ${ }^{1}$ Anna Bihun ${ }^{1}$
}

Received: 17 August 2016/Revised: 29 October 2016/Accepted: 24 November 2016/

Published online: 30 November 2016

(C) The Author(s) 2016. This article is published with open access at Springerlink.com

\begin{abstract}
Copolymerization of ethylene with norbornene (E/NB) and ethylene with 1-octene (E/Oct) is performed using supported ionic liquid (SIL) systems, in which metallocene $\left(\mathrm{Cp}_{2} \mathrm{VCl}_{2}\right)$ or post-metallocene $\left[\mathrm{VCl}_{2}(\right.$ salenCl 2$\left.)\right]$ vanadium catalysts are immobilized in pyridinium chloroaluminate ionic liquid supported on silica. The studied SIL catalysts show higher activities as well as stability than their nonsupported analogues. In addition, higher activities and better comonomer incorporation are observed for norbornene (above $30 \mathrm{~mol} \%$ ). The comonomer incorporation has considerable influence on copolymer molecular weight $\left(M_{\mathrm{w}}\right)$, melting temperature, crystallinity degree, and microstructure of the copolymers. Molecularweight distribution is relatively narrow $\left(1.5 \leq M_{\mathrm{w}} / M_{\mathrm{n}} \leq 3.0\right)$, which indicates the presence of single-site catalyst systems.
\end{abstract}

Keywords Copolymerization · Ionic liquid · Silica · Vanadium catalyst · Polyolefins

\section{Introduction}

Norbornene is the most often applied cyclic olefin in ethylene copolymerization catalyzed mainly by zirconium, titanium [1-5], and recently also by vanadium compounds [6-10]. Ethylene-norbornene copolymers (E/NB) constitute usually amorphous and chemically resistant material, which is excellent barrier to water vapor and is characterized by a wide range of glass transition temperatures, from

Electronic supplementary material The online version of this article (doi:10.1007/s00289-016-18661) contains supplementary material, which is available to authorized users.

Wioletta Ochędzan-Siodłak

wsiodlak@uni.opole.pl

1 Faculty of Chemistry, University of Opole, Oleska 48, 45-052 Opole, Poland 
room temperature up to about $220^{\circ} \mathrm{C}$. Rigid bicycle monomer units ensure excellent transparency and high refractive index. It is biocompatible and easy processing material. Diversity in incorporation of norbornene units results in diversity of properties $[1,7,11,12]$. E/NB copolymers are suitable for, e.g., coating of high memory CD and DVD plates, production of lenses, prisms, medical equipment, pharmaceutical foils pack blister type, ampoules, and phials, composite package foil for food, and metalized film capacitor, microtiter plates, or binder resin for toner color printers $[1,11,13]$. Depending on the type of catalyst system applied to copolymerization, various microstructures of $\mathrm{E} / \mathrm{NB}$ chain can be obtained, which in turn influences macroscopic properties of polymer product. In case of metallocene catalysts, incorporation of norbornene units is not as easy as ethylene $[11,12]$. In general, the metallocene catalysts reveal a low tendency to create blocks of norbornene. To obtain alternating copolymer, it is necessary to increase the norbornene incorporation and this occurs at a high ratio of norbornene to ethylene $[1,11]$. Norbornene microblocks can be obtained only at high concentration of norbornene in reaction mixture. Structure of ligands in metallocene complexes also influences on the number of norbornene units connected together in the molecular chain (length of comonomer blocks) [11, 12]. Thus, catalyst structure determines copolymer composition, comonomer distribution in polymer chain, like also stereochemistry [11, 14]. For E/NB copolymerization, usually, homogeneous catalysts are applied [1-14], and less often heterogeneous catalysts are reported [15-17]. The problem is poor norbornene incorporation, which is possible at low ethylene pressure [16].

For ethylene/1-olefin copolymerization, both homogeneous and heterogeneous catalysts are applied [17-21]. The worldwide production of copolymers of ethylene with 1-butene, 1-hexene, 1-octene, or 4-methyl-1-pentene is dominated by ethylene/ 1-octene copolymers which reveal the best mechanical properties as compared to other 1-olefins with even number of carbon atoms [22]. Such copolymers are applied as toughness modifier in ethylene/propylene copolymers [23] as well as in production of pipes and profiles. It should be noted that about $90 \%$ of ethylene/1olefin copolymers are produced using supported Ziegler-Natta catalysts, $10 \%$ are produced using metallocene catalysts, most often complexes of metals group 4, mainly zirconium or titanium [24, 25]. Only scarce literature data concerns application of vanadium catalysts for ethylene/1-octene copolymerization. Although the vanadium compounds reveal lower activities as compared to analogous zirconium, titanium, or hafnium, they give better 1-octene incorporation in copolymer chain [26]. In case of heterogeneous catalyst systems for ethylene/1octene copolymerization, both method of heterogenization and type of solid support have considerable influence on the amount of comonomer units incorporated in polymer chain, which can be increased [27] or decreased [28].

An interesting method of catalyst heterogenization is SIL (Supported Ionic Liquid). The homogeneous catalyst is placed in thin ionic liquid film, which in turn is anchored on solid porous support (e.g., $\mathrm{MgO}, \mathrm{SiO}_{2}$, and $\mathrm{Al}_{2} \mathrm{O}_{3}$ ) [29]. Thus, the SIL systems combine the advantages of both homogeneous and heterogeneous catalysts while reducing their disadvantages [30]. The SIL systems can be successfully applied for ethylene polymerization [31-33]. The silica covered by 
imidiazolium or pyridinium chloroaluminate ionic liquid is applied as support of the zirconium, titanium, or vanadium catalysts. In results, not only the active catalyst systems are obtained, but also polymer of atypical morphology. To date, such SIL systems were not applied to copolymerization.

This work presents the first results of ethylene/norbornene and ethylene/1-octene copolymerizations performed using the SIL systems, in which metallocene and postmetallocene vanadium catalysts are immobilized on pyridinium chloroaluminate ionic liquid supported on silica. The influence of the type of catalyst is discussed. The selected properties of copolymers are described.

\section{Experiment}

\section{Materials}

Ethylene (Linde AG Gaz) and nitrogen (Polgaz, Poland) were dried using sodium metal supported on alumina. Nitrogen was earlier dried over sodium hydroxide and phosphorus pentoxide. Hexane (Avantor, Poland) was purified by concentrated sulphuric acid (VI) $95 \mathrm{wt} \%$, dried by sodium hydroxide and distilled to obtain fraction $65-70{ }^{\circ} \mathrm{C}$. The hexane was stored over sodium metal, and shortly before reaction, it was distilled over benzophenone. Toluene (Avantor, Poland) was distilled over sodium metal. Methylene dichloride (Avantor, Poland) was distilled over phosphorus pentoxide. Diethyl ether (Avantor, Poland) was stored over sodium metal. Dichlorobis( $\eta$-cyclopentadienyl)vanadium(IV) $-\mathrm{Cp}_{2} \mathrm{VCl}_{2}$ (Sigma-Aldrich), diethylaluminum chloride- $\mathrm{AlEt}_{2} \mathrm{Cl}$ (Sigma-Aldrich, $1 \mathrm{M}$ in hexane), silica, particle size 10-20 nm (Sigma-Aldrich), methanol (Avantor, Poland), aluminium chloride $-\mathrm{AlCl}_{3}$ (Sigma-Aldrich), phosphorus pentoxide- $\mathrm{P}_{2} \mathrm{O}_{5}$ (Avantor, Poland), norbornene (Sigma-Aldrich), 1-octene, pyridine, 3-chloropropyltriethoxysilane, and ethyl trichloroacetate-ETA (Sigma-Aldrich) were applied as purchased. Vanadium salen complex, $N, N^{\prime}$-ethylenebis(5-chlorosalicylideneiminato)vanadium(IV) dichloride $-\mathrm{VCl}_{2}($ salenCl 2$)$, was obtained and prepared according to the published procedure [28]. Ionic liquid, 1-[3-(triethoxysilyl)propyl]pyridinium chloride, was obtained according to the published procedure [33].

\section{Instruments}

FTIR analyses were accomplished using a Nicole Nexus 2002 FTIR spectrometer from 4000 to $400 \mathrm{~cm}^{-1}$ with a $1 \mathrm{~cm}^{-1}$ resolution. The FTIR analyses of the SIL system samples from each step of the synthesis were investigated in Nujol $\mathrm{KBr} / \mathrm{KBr}$. ${ }^{13} \mathrm{C}$ NMR spectra of the polymers were recorded on a Bruker Ultrashield spectrometer $(400 \mathrm{MHz})$ in $o$-dichlorobenzene- $d_{4}$ solvent. Calculations of total comonomer incorporation [14, 34] are presented in Supplementary Materials. Nitrogen adsorption-desorption isotherms were obtained on a ASAP 2020 (Micromeritics) instrument after out gassing the samples in vacuum at $150{ }^{\circ} \mathrm{C}$ for $12 \mathrm{~h}$ prior to the measurements. The total surface areas were calculated according to the Brunauer-Emmett-Teller (BET) method, and the average pore diameter was 
calculated following Barrett-Joyner-Halenda (BJH) method. Atomic absorption spectrometry (AAS) using an ICE 3500 model (Thermo Electron Corporation) was used to determine amount of $\mathrm{V}$ element. The crystallinity and the melting temperature of the polyethylene samples were estimated with a DSC 2010 TA instruments. The polymer crystallinity degree was calculated using the equation: $X=\left(\Delta H_{\mathrm{f}} / \Delta H_{\mathrm{t}, \mathrm{c}}\right) \times 100 \%$, where $\Delta H_{\mathrm{f}}$-enthalpy of fusion of the polyethylene sample, $\Delta H_{\mathrm{t}, \mathrm{c}}$ - enthalpy of fusion of standard $=290 \mathrm{~J} \mathrm{~g}^{-1}$, and $X$-crystallinity degree, $\%$.

Gel permeation chromatography was used to determine the molecular weight and molecular-weight distribution of the polymer samples on Waters Alliance GPCV 2000 apparatus using 1,2,4-trichlorobenzene as the solvent at $142{ }^{\circ} \mathrm{C}$. The data were analyzed using polystyrene calibration curves.

\section{Synthesis of SIL vanadium catalyst}

All experimental steps have to be carried out under an inert atmosphere. The commercial silica material of particle size $10-20 \mathrm{~mm}(3.00 \mathrm{~g})$ was calcined for $4 \mathrm{~h}$ at $500{ }^{\circ} \mathrm{C}$ and stored under argon. The calcination of silica results, according to the Zhuravlev model [35], in the concentration of isolated and geminal $-\mathrm{OH}$ groups on the silica surface in the range of 1.55 and $0.25 \mathrm{OH} \mathrm{nm}^{-2}$, respectively. The calcined silica was placed in a round bottom flask, and 1-[3(-triethoxysilyl)propyl]pyridinium chloride was added in a molar ratio of 10:1 in dichloromethane $(80 \mathrm{~mL})$. The mixture was stirred at reflux for $24 \mathrm{~h}$. Solvent and ethanol produced during reaction were distilled off. The remaining solid was dried under vacuum, then extracted for $24 \mathrm{~h}$ with boiling dichloromethane in a Soxhlet apparatus, and dried under vacuum. In results, the silica modified by 1-[3-(triethoxysilyl)propyl]pyridinium chloride was obtained in the form of white powder. Such obtained solid was then added to a solution of $\mathrm{AlCl}_{3}\left(5.0 \times 10^{-3} \mathrm{~mol}\right)$ in toluene $(50 \mathrm{~mL})$ and left stirring for $2 \mathrm{~h}$ at room temperature. After filtration in the Schlenk apparatus, the support was washed with hexane $(4.0 \times 30 \mathrm{~mL})$, dried under vacuum, extracted for $24 \mathrm{~h}$ with boiling dichloromethane in the Soxhlet apparatus, and dried under reduced pressure. The solid was mixed with $\left(2.0 \times 10^{-3} \mathrm{~mol}\right) \mathrm{AlEt}_{2} \mathrm{Cl}$ in hexane $(50 \mathrm{~mL})$ in a ball mill for $2 \mathrm{~h}$. The obtained support was filtered in Schlenk apparatus, washed with hexane $(4 \times 30 \mathrm{~mL})$, and dried under reduced pressure. In results, the ionic liquid-silica support with alkylaluminium chloride anions was obtained in the form of off-white powder. The prepared support $(1.00 \mathrm{~g})$ was mixed with catalyst precursor $\mathrm{Cp}_{2} \mathrm{VCl}_{2}$ or $\mathrm{VCl}_{2}\left(\mathrm{salenCl}_{2}\right)\left(2.8 \times 10^{-5} \mathrm{~mol} \mathrm{~V}\right)$ dissolved in deoxygenated toluene $(3 \mathrm{~mL})$ and hexane $(50 \mathrm{~mL})$, in a ball mill for $24 \mathrm{~h}$. The obtained catalyst system was filtered in Schlenk apparatus, washed with hexane $(4 \times 20 \mathrm{~mL})$, and dried under nitrogen stream. The final SIL systems were in the form of slightly green powder.

The amount of ionic liquid is $4.3 \times 10^{-3}$ mol per gram, and the SIL system was estimated by elemental analysis for the percentage of nitrogen element. The amount of the $\mathrm{Cp}_{2} \mathrm{VCl}_{2}$ and $\mathrm{VCl}_{2}($ salenCl 2$)$ catalysts immobilized on the SIL support equals $7.1 \times 10^{-6}$ and $6.5 \times 10^{-6} \mathrm{~mol} \mathrm{~V}$ in $1 \mathrm{~g}$ of the system, respectively, as determined by atomic absorption spectrometry analysis (AAS) using the transition metal content. 


\section{Synthesis of ethylene/norbornene and ethylene/1-octene (co)polymers}

The glass reactor $500 \mathrm{~mL}$ was filled with nitrogen, and hexane $(150 \mathrm{~mL})$, norbornene or 1-octene comonomer $(0.05-1.50 \mathrm{~mol} / \mathrm{L}), \mathrm{AlEt}_{2} \mathrm{Cl}\left(3.0 \times 10^{-3}\right.$ $\mathrm{mol})$, ethyl trichloroacetate $(\mathrm{ETA})\left(1.0 \times 10^{-3} \mathrm{~mol}\right)$, the SIL catalyst system $(0.300 \mathrm{~g})$, or non-supported $\mathrm{Cp}_{2} \mathrm{VCl}_{2}$ or $\mathrm{VCl}_{2}\left(\mathrm{salenCl}_{2}\right)$ catalysts $\left[2.0 \times 10^{-6}\right.$ or $2.0 \times 10^{-5} \mathrm{~mol}$ of vanadium as toluene solution $\left.(3 \mathrm{~mL})\right]$, and ethylene was successively added. Reaction was carried out for $10-60 \mathrm{~min}$ at $0.5 \mathrm{MPa}$ and $30{ }^{\circ} \mathrm{C}$. The reaction was terminated by closure of ethylene feeding, reduction of the pressure to $0.1 \mathrm{MPa}$, and addition of acidified methanol. The polymer product was filtered, washed by hexane, methanol, and dried at $50{ }^{\circ} \mathrm{C}$ to constant mass. Such prepared samples were used for further analyses. To ensure reproducibility of the results, each (co)polymerization reaction was repeated.

Leaching experiment for SIL catalytic system was performed in inert atmosphere to glass flask equipped with mechanical stirrer and heating jacket by adding hexane $(150 \mathrm{~mL}), \mathrm{AlEt}_{2} \mathrm{Cl}\left(3.0 \times 10^{-3} \mathrm{~mol}\right)$, and the vanadium SIL catalyst system $(0.300 \mathrm{~g})$. The mixture was mixed vigorously at $30{ }^{\circ} \mathrm{C}$ for $30 \mathrm{~min}$. Maintaining inert atmosphere, the solid was filtered and hexane phase was placed into reactor, where it was taken into the ethylene flush at typical polymerization conditions $(0.5 \mathrm{MPa}$, $\left.30{ }^{\circ} \mathrm{C}, 30 \mathrm{~min}\right)$. The solution was transparent, and no polymer product was obtained. The absence of vanadium compounds in the hexane phase was also confirmed by AAS method.

\section{Results and discussion}

\section{Characterization of SIL vanadium catalyst}

The anchorage of ionic liquid on the silica support was confirmed by Fourier transform infrared (FTIR) spectroscopy (Fig. 1). The non-modified silica shows characteristic band at $3691 \mathrm{~cm}^{-1}$ ( $\mathrm{Si}-\mathrm{OH}$ stretching vibrations), like also at 1091 , and $818 \mathrm{~cm}^{-1}$ (Si-O-Si stretching vibrations). The band at $3691 \mathrm{~cm}^{-1}$ disappears when the silica reacts with 1-[3-(triethoxysilyl)propyl]pyridinium chloride ionic liquid, and further, at the addition of alkylaluminium compounds. The presence of the ionic liquid in the prepared silica supports is also proved by appearance of characteristic bands at 1635,1583 , and $680 \mathrm{~cm}^{-1}$, assigned to $\mathrm{C}-\mathrm{N}$ and $\mathrm{C}-\mathrm{C}$ stretching vibrations as well as out of plane vibrations of the pyridinium ring.

Based on our previous study [33], the silica material with the narrow, but deep pores was chosen. The Brunauer-Emmett-Teller (BET) analysis shows that for this silica support, introduction of the ionic liquid and further modification by creation of more bulky chloroaluminate anion result in decrease of the surface area from 457 to $67 \mathrm{~m}^{2} / \mathrm{g}$, like also in decreases of the pore volume from $0.56 \mathrm{~cm}^{3} / \mathrm{g}$ to $0.28 \mathrm{~cm}^{3}$ / g. Simultaneously, the average pore width ( 4 V/A by BET) slightly increases, from 4.9 to $5.5 \mathrm{~nm}$. This shows that the pores in silica were considerably sealed by the ionic liquid film. In a consequence, the ionic liquid layer, evenly placed on the silica surface, ensures evenly distribution of the catalyst precursor. 


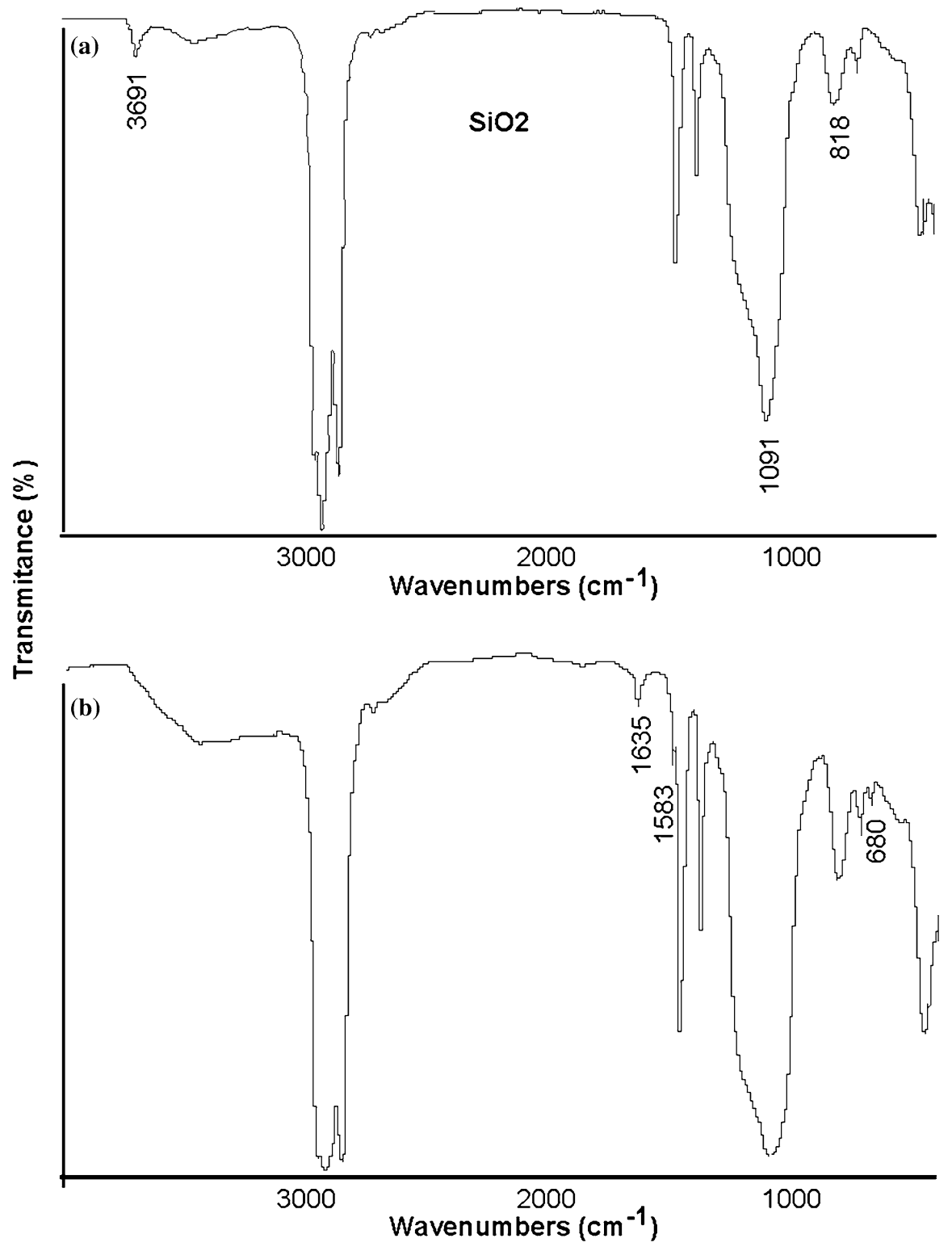

Fig. 1 FTIR spectra: a calcined silica and b SIL catalyst system

SEM images (Fig. 2a, b) confirm that the silica calcined has very regular and spherical shape of single, not agglomerated granules, which become smoother after immobilization of the ionic liquid. Breaking of some granules results in consecutive operation steps (in ball mill). 

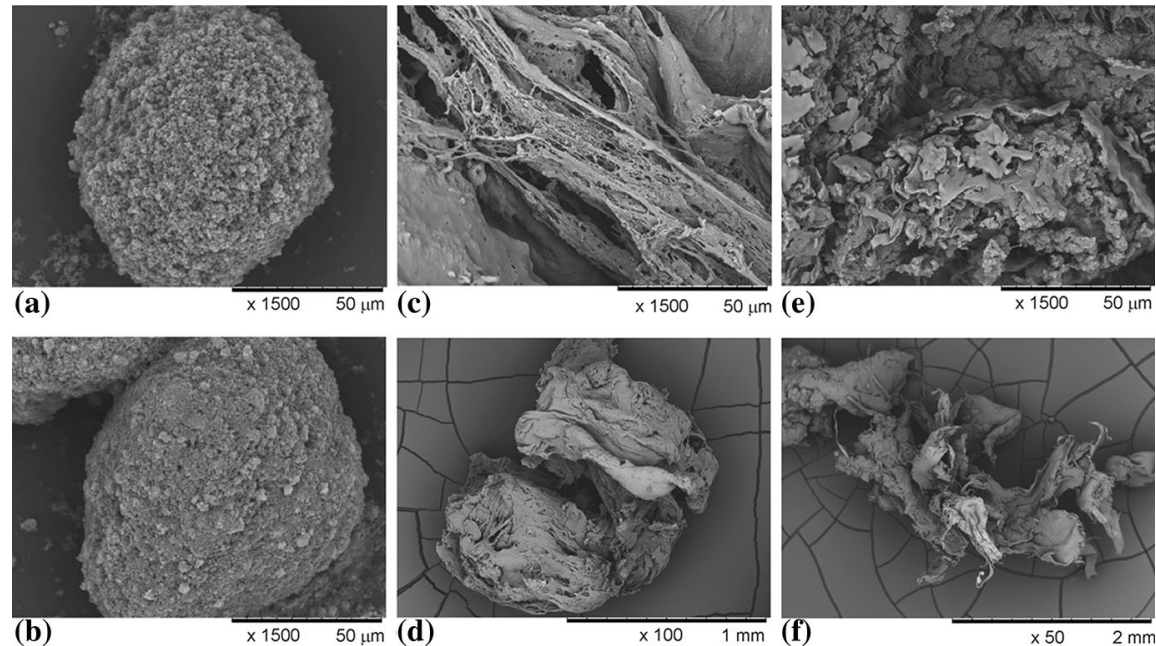

Fig. 2 SEM images: a calcined silica, b SIL catalyst system; c, d ethylene/norbornene copolymer (Table 1, item 5); e, f ethylene/1-octene copolymers (Table 2, item 7)

\section{Copolymerization of ethylene with norbornene}

Ethylene-norbornene copolymerizations were performed using the SIL systems with $\mathrm{Cp}_{2} \mathrm{VCl}_{2}$ and $\left.\mathrm{VCl}_{2}(\text { salenCl})_{2}\right)$ at the initial concentration of norbornene in the range of $0.05-1.5 \mathrm{~mol} / \mathrm{L}$ (Table 1 ). The addition of ETA re-activator greatly improves activity. For both SIL systems, increase of NB concentration results in an increase of activity, which reaches maximum at 0.3 and $0.6 \mathrm{~mol} / \mathrm{L}$, respectively, for $\mathrm{SIL} / \mathrm{VCl}_{2}\left(\right.$ salenCl${ }_{2}$ ) and SIL/Cp $\mathrm{VCl}_{2}$ systems (Table 1 , items 6,17 ). For the SIL/ $\mathrm{VCl}_{2}\left(\right.$ salenCl$\left._{2}\right)$ system, the highest activity in copolymerization is comparable to that for ethylene homopolymerization, whereas for the $\mathrm{SIL} / \mathrm{Cp}_{2} \mathrm{VCl}_{2}$ system, the highest activity in copolymerization is greater to that for ethylene homopolymerization. Further increase of the NB concentration results in slow decline of the activity (Fig. 3a, b). Similar behavior was also reported for other catalysts [8, 9]. The observed decrease of the activity is lower for the $\mathrm{SIL} / \mathrm{Cp}_{2} \mathrm{VCl}_{2}$ system. This may provide for greater stability of metallocene as compared with the postmetallocene analogue, suggesting that ligand expansion around a transition metal in the case of SIL system is not favorable. It means that steric effect exerts greater influence on catalytic activity toward E/NB copolymerization [9].

Figure 4 presents selected ${ }^{13} \mathrm{C}$ NMR spectra of E/NB copolymers obtained using the studied SIL systems at different NB concentrations in the polymerization feed. Incorporation of norbornene in the polymer chain is confirmed by the presence of characteristic signals at $46.7,41.2$, and $32.4 \mathrm{ppm}$, assigned, respectively, to the carbon atoms $\mathrm{C} 2 / \mathrm{C} 3, \mathrm{C} 1 / \mathrm{C} 4$, and $\mathrm{C} 7$ of the norbornene unit as well as at 29.3-29.8 ppm assigned to $\mathrm{C} 5 / \mathrm{C} 6$ and $\mathrm{CH}_{2}$ sequences [14]. Percentage norbornene incorporated in the polymer chain is in the range of 3.6-35.3 mol\%. Incorporation increases almost linearly with increase of the initial NB concentration feed and is 
Table 1 Results of ethylene/norbornene copolymerization

\begin{tabular}{|c|c|c|c|c|c|c|c|}
\hline Item & Catalyst & $\begin{array}{l}\text { NB feed } \\
(\mathrm{mol} / \mathrm{L})\end{array}$ & $\begin{array}{l}\text { Yield } \\
(\mathrm{g})\end{array}$ & $\begin{array}{l}\text { Activity } \times 10^{-4} \\
\left(\mathrm{~g} / \mathrm{mol}_{\mathrm{V}}\right)\end{array}$ & $\begin{array}{l}M_{\mathrm{w}} \\
(\mathrm{kg} / \mathrm{mol})\end{array}$ & $M_{\mathrm{w}} / M_{\mathrm{n}}$ & $\begin{array}{l}\text { NB incorp. } \\
(\mathrm{mol} \%)\end{array}$ \\
\hline $1^{\mathrm{a}}$ & \multirow[t]{11}{*}{$\mathrm{SIL} / \mathrm{VCl}_{2}\left(\mathrm{salenCl}_{2}\right)$} & 0.00 & 2.7 & 136 & 1421 & 1.7 & - \\
\hline 2 & & 0.00 & 13.1 & 670 & 1233 & 1.6 & - \\
\hline 3 & & 0.05 & 10.0 & 510 & 1128 & 1.6 & 3.6 \\
\hline $4^{\mathrm{a}}$ & & 0.10 & 0.8 & 39 & 1216 & 1.7 & 5.0 \\
\hline 5 & & 0.10 & 11.9 & 610 & 943 & 1.6 & 7.0 \\
\hline 6 & & 0.30 & 13.1 & 670 & 286 & 1.6 & 13.8 \\
\hline 7 & & 0.50 & 11.3 & 580 & 367 & 1.6 & 17.4 \\
\hline 8 & & 0.60 & 10.0 & 510 & 444 & 1.7 & 19.6 \\
\hline 9 & & 0.90 & 6.5 & 335 & 510 & 1.8 & 23.5 \\
\hline 10 & & 1.00 & 5.1 & 260 & 368 & 2.0 & 25.3 \\
\hline 11 & & 1.50 & 1.1 & 56 & 262 & 2.8 & 30.4 \\
\hline 12 & \multirow[t]{9}{*}{$\mathrm{SIL} / \mathrm{Cp}_{2} \mathrm{VCl}_{2}$} & 0.00 & 7.3 & 340 & 1070 & 1.5 & - \\
\hline 13 & & 0.05 & 3.5 & 166 & 879 & 1.6 & 3.5 \\
\hline 14 & & 0.10 & 5.8 & 273 & 537 & 1.6 & 6.8 \\
\hline 15 & & 0.30 & 10.3 & 483 & 453 & 1.9 & 10.2 \\
\hline 16 & & 0.50 & 12.4 & 570 & 498 & 2.0 & 15.9 \\
\hline 17 & & 0.60 & 13.3 & 625 & 661 & 2.0 & 18.6 \\
\hline 18 & & 0.90 & 12.2 & 574 & 543 & 2.5 & 24.3 \\
\hline 19 & & 1.00 & 10.8 & 505 & 265 & 2.9 & 26.1 \\
\hline 20 & & 1.50 & 7.6 & 357 & 225 & 3.0 & 35.3 \\
\hline $21^{\mathrm{b}}$ & \multirow[t]{4}{*}{$\mathrm{VCl}_{2}\left(\right.$ salenCl $\left.\mathrm{l}_{2}\right)$} & 0.00 & 6.1 & 305 & 840 & 1.6 & - \\
\hline $22^{\mathrm{c}}$ & & 0.00 & 25.5 & 127 & 1472 & 1.5 & - \\
\hline $23^{\mathrm{b}}$ & & 1.00 & 2.4 & 120 & 426 & 3.2 & 27.8 \\
\hline $24^{\mathrm{c}}$ & & 1.00 & 18.7 & 94 & 503 & 3.4 & 27.2 \\
\hline $25^{\mathrm{b}}$ & \multirow[t]{4}{*}{$\mathrm{Cp}_{2} \mathrm{VCl}_{2}$} & 0.00 & 1.6 & 79 & 790 & 1.7 & - \\
\hline $26^{\mathrm{c}}$ & & 0.00 & 6.7 & 34 & 1278 & 1.6 & - \\
\hline $27^{\mathrm{b}}$ & & 1.00 & 3.4 & 170 & 392 & 2.8 & 24.5 \\
\hline $28^{\mathrm{c}}$ & & 1.00 & 13.7 & 68 & 470 & 2.9 & 23.6 \\
\hline
\end{tabular}

Reaction conditions: catalyst system $=0.300 \mathrm{~g}$, temperature $=30{ }^{\circ} \mathrm{C}$, ethylene pressure $=0.5 \mathrm{MPa}$, time $=30 \mathrm{~min}$., solvent - hexane $=150 \mathrm{~mL}$, activator- $\mathrm{AlEt}_{2} \mathrm{Cl}=3.0 \times 10^{-3} \mathrm{~mol}$, ethyl trichloroacetate-ETA $=1.0 \times 10^{-3} \mathrm{~mol}$

Standard deviation does not exceed $7 \%$ for yield and $0.04 \%$ for $M_{\mathrm{w}}$ and $M_{\mathrm{w}} / M_{\mathrm{n}}$

${ }^{a}$ Without ETA

${ }^{\text {b }}$ Catalyst $=2.0 \times 10^{-6} \mathrm{~mol}$

${ }^{c}$ Catalyst $=2.0 \times 10^{-5} \mathrm{~mol}$

comparable for both studied SIL catalysts (Table 1, items 3, 5-11, 13-20, Fig. 3a, b). The highest NB percentage equals 30.4 and $35.3 \mathrm{~mol} \%$ for $\mathrm{SIL} / \mathrm{VCl}_{2}\left(\operatorname{salenCl}_{2}\right)$ and $\mathrm{SIL} / \mathrm{Cp}_{2} \mathrm{VCl}_{2}$, respectively (Table 1 , items 11,20 ). This indicates that $\mathrm{NB}$ incorporation is rather independent on the catalyst structure [9]. It should be noted 
(a)

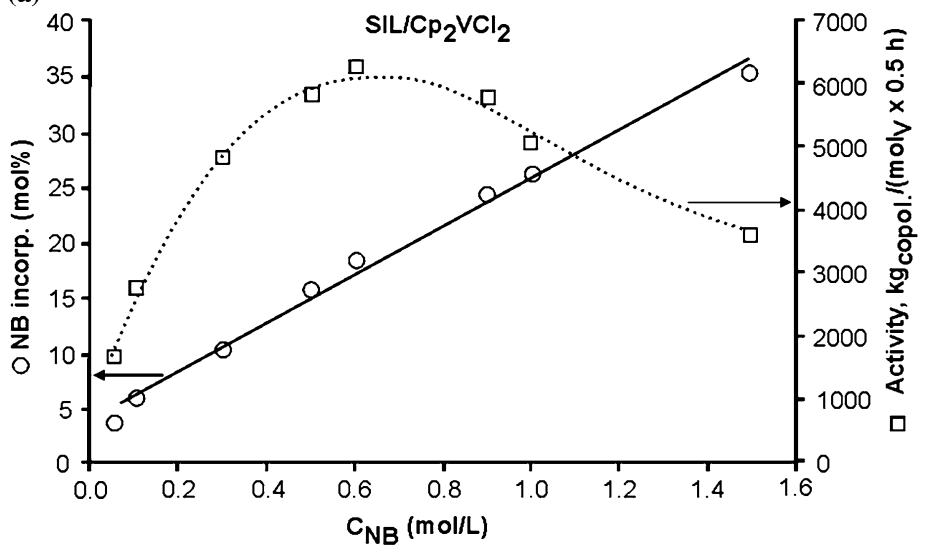

(b)

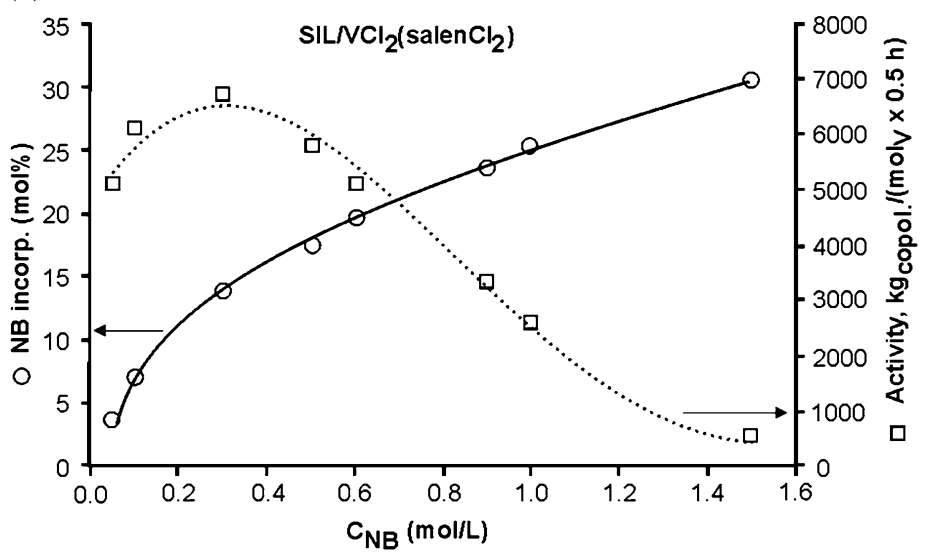

(c)

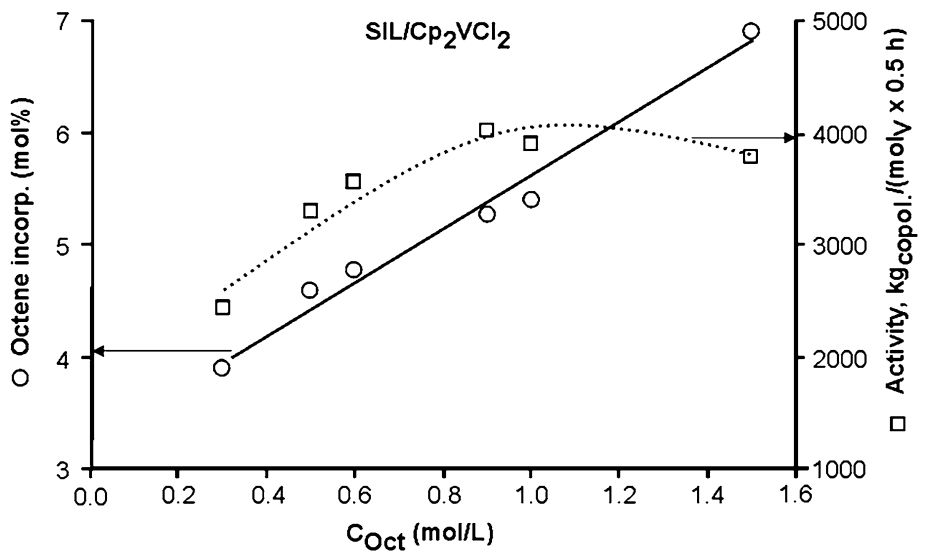

Fig. 3 Influence of comonomer concentration on its incorporation and catalyst activity 


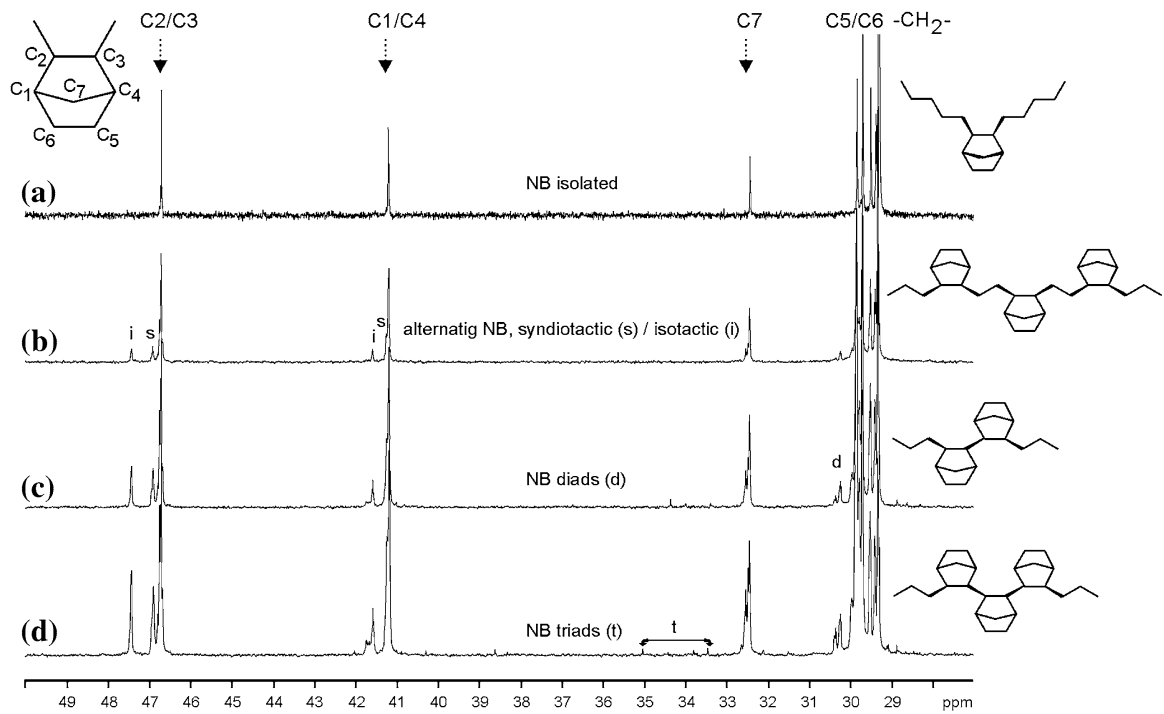

Fig. $4{ }^{13} \mathrm{C}$ NMR spectra of ethylene/norbornene copolymers (Table 1, items 14, 17, 18, and 20) with various NB incorporation: $a(6.8 \mathrm{~mol} \%), b(18.6 \mathrm{~mol} \%), c(24.3 \mathrm{~mol} \%)$, and $d(35.3 \mathrm{~mol} \%)$

that the addition of ETA re-activator not only improves activity, but also NB incorporation (Table 1, items 4, 5).

For comparison, (co)polymerization was also performed using non-supported homogeneous catalysts, $\mathrm{VCl}_{2}\left(\mathrm{salenCl}_{2}\right)$ and $\mathrm{Cp}_{2} \mathrm{VCl}_{2}$, at the same vanadium concentration as well as at tenfold excess as compared to SIL systems (Table 1, items 21-28). Both in ethylene homopolymerization as well as copolymerization, higher activity shows the SIL systems at comparable catalyst concentration. Increase of the catalyst concentration results in an increase of yield, but a decrease of activity, while the NB incorporation remains on the same level (Table 1, items $23,24,27,28)$, as it is also reported in the literature $[8,36]$. It should also be noted that the NB incorporation is comparable for all studied catalysts at the same initial concentration.

It is also worth noting that at comparable concentration of norbornene in the copolymerization feed, the studied vanadium SIL catalysts ensure a better NB incorporation than homogeneous metallocene and post-metallocene vanadium catalysts reported in the literature [6-8, 37]. In case of heterogeneous catalysts, the scarce literature data concern only zirconocene catalysts anchored on organic or inorganic supports and activated by MAO. The NB incorporation varies from 0.2 to $40 \mathrm{~mol} \%$ [15, 16]. According to Goretzki et al. [16], heterogeneous zirconocene catalysts on silica support enable incorporation of the NB units only at a very low ethylene concentration (0.025 MPa). Our results show that the SIL systems with silica modified by the ionic liquid allow obtaining the copolymer with the NB incorporation more than $30 \mathrm{~mol} \%$ at much higher ethylene concentration (0.5 MPa). This is result of the presence of the ionic liquid medium and pseudoheterogeneous SIL system. The catalyst, dissolved in the ionic liquid phase, 


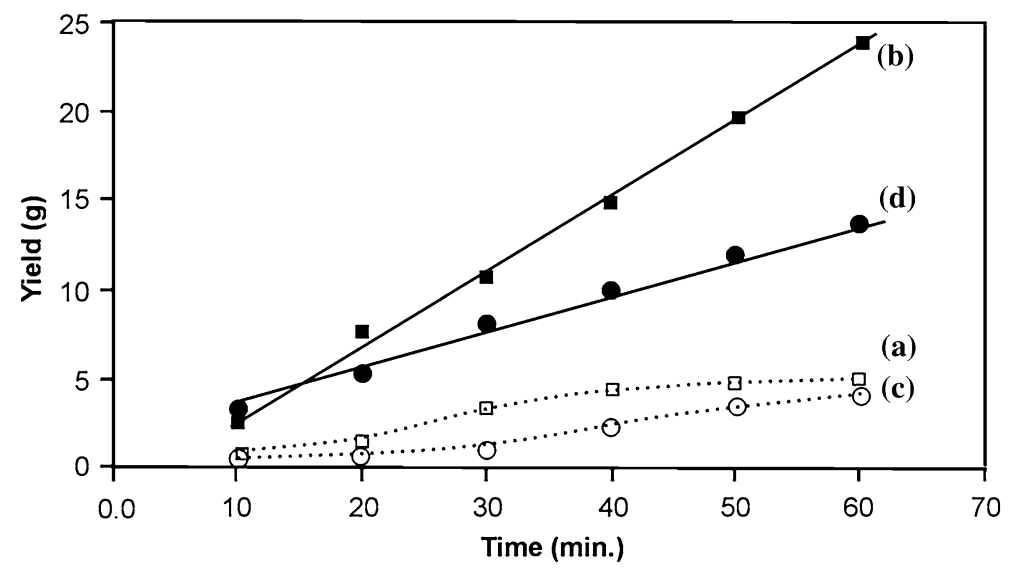

Fig. 5 Influence of reaction time on copolymer yield. Catalyst $\mathrm{Cp}_{2} \mathrm{VCl}_{2}$, comonomer initial concentration-1 mol/L, molar ratio $\mathrm{Al} / \mathrm{V}-1500$, ETA-1.0 $\times 10^{-3} \mathrm{~mol} ; a$ ethylene/norbornene, homogeneous catalyst; $b$ ethylene/norbornene, SIL system; $c$ ethylene/1-octene, homogeneous catalyst; $d$ ethylene/1-octene, SIL system

maintains its homogeneous properties. The ionic liquid, covalently anchored on the solid silica support, makes the whole system heterogeneous.

For the SIL/C $\mathrm{C}_{2} \mathrm{VCl}_{2}$ system, a linear increase of the yield in copolymerization time was observed. For homogeneous catalyst, increase of the yield is observed only up to about 40 min of reaction (Fig. 5a, b). This confirms a higher stability of the SIL system as compared to the homogeneous analogue.

The microstructure of copolymer chain varies depending on the NB incorporation. As can be seen in Fig. 4a, when NB constitutes less than $7 \mathrm{~mol} \%$ of the copolymer, only signals assigned to the isolated $\mathrm{NB}$ units can be observed (46.7 ppm C2/C3, $41.2 \mathrm{ppm} \mathrm{C1/C4,} 32.4$ ppm C7, and 29.3-29.8 ppm C5/C6) (Table 1, items 3-5, 13, 14). Additional signals, assigned to alternating NB units, appear at incorporation $13.8 \mathrm{~mol} \%$ and higher (Table 1, items 6-8, 16, 17). The syndiotactic (s) and isotactic (i) structures can be differentiated (Fig. 4b), based on the signal at 47.4 and $46.9 \mathrm{ppm}$, respectively. The relative equal intensities of these signals indicate that the copolymer has a random tacticity [38]. At higher NB incorporation, 23.5 and $23.6 \mathrm{~mol} \%$, signals from NB diads, appear at 30.2-30.4 ppm (Table 1, items 9, 28) (Fig. 4c). Further increase of the NB incorporation from 24.3 and up to maximum obtained $35.3 \mathrm{~mol} \%$ also results in appearance of NB triads (Table 1, items 10, 11, 18-20, 23, 24, 27, 28) at 28.3-29.2 and 33.4-35.1 ppm (Fig. 4d). Appearance of triads and longer microblocks at incorporation higher than $20 \mathrm{~mol} \%$ is also reported in the literature [3, 11]. Increase of comonomer incorporation decreases the number of isolated NB units, but increases the number of alternating NB units as well as the number of NB diads and triads [10].

The NB incorporation has considerable influence on copolymer molecular weight $\left(M_{\mathrm{w}}\right)$ and molecular-weight distribution $\left(M_{\mathrm{w}} / M_{\mathrm{n}}\right)$ (Table 1). Narrow and unimodal $M_{\mathrm{w}} / M_{\mathrm{n}}$ indicates that single type of active centers participates in copolymerization 


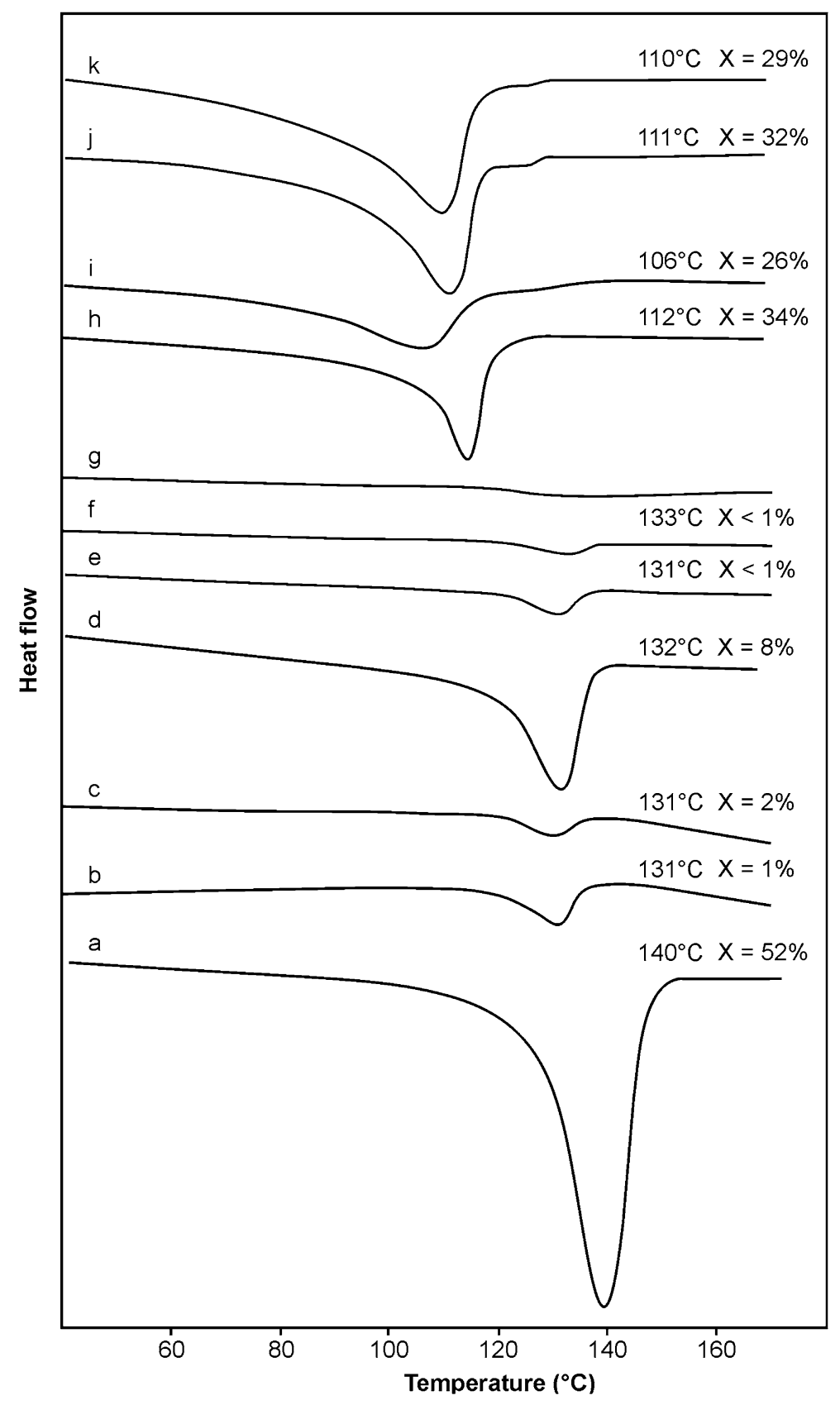

Fig. 6 Second heating DSC thermograms of the polymers: $a$ polyethylene; $b, c$ ethylene/norbornene (Table 1, items 17 and 20); $d, e$ ethylene/norbornene (10 and $60 \mathrm{~min}) ; f, g$ ethylene/norbornene (homogeneous catalyst, 10 and $60 \mathrm{~min}$ ); $h, i$ ethylene/1-octene (Table 2, items 5 and 8); $j, k$ ethylene/1octene (homogeneous catalyst, 10 and $60 \mathrm{~min}$ ); $\mathrm{X}$-crystallinity degree 
Table 2 Results of ethylene/1-octene copolymerization

\begin{tabular}{llllllllll}
\hline Item & Catalyst & $\begin{array}{l}\text { Oct } \\
\text { feed } \\
(\mathrm{mol} / \\
\mathrm{L})\end{array}$ & $\begin{array}{l}\text { Yield } \\
(\mathrm{g})\end{array}$ & $\begin{array}{l}\text { Activity } \times 10^{-4} \\
(\mathrm{~g} / \mathrm{mol})\end{array}$ & $\begin{array}{l}M_{\mathrm{w}} \\
(\mathrm{kg} / \mathrm{mol})\end{array}$ & $\begin{array}{l}M_{w} / \\
M_{n}\end{array}$ & $\begin{array}{l}\text { Oct } \\
\text { incorp. } \\
(\mathrm{mol} \%)\end{array}$ & $\begin{array}{l}T_{\mathrm{m}} \\
\left({ }^{\circ} \mathrm{C}\right)\end{array}$ & $\begin{array}{l}X^{\mathrm{a}} \\
(\%)\end{array}$ \\
\hline 1 & \left.${\mathrm{SIL} / \mathrm{VCl}_{2}\left(\mathrm{salenCl}_{2}\right)}\right)$ & 0.50 & 7.2 & 369 & 511 & 2.5 & 4.4 & 128 & 40 \\
2 & & 1.00 & 4.2 & 214 & 396 & 3.0 & 5.0 & 122 & 38 \\
3 & $\mathrm{SIL} \mathrm{Cp}_{2} \mathrm{VCl}_{2}$ & 0.30 & 5.1 & 239 & $\mathrm{nd}$ & $\mathrm{nd}$ & 3.9 & 120 & 39 \\
4 & & 0.50 & 7.0 & 328 & 427 & 2.8 & 4.8 & 115 & 35 \\
5 & & 0.60 & 7.6 & 358 & 358 & 2.8 & 4.9 & 112 & 34 \\
6 & & 0.90 & 8.6 & 403 & $\mathrm{nd}$ & $\mathrm{nd}$ & 5.2 & 111 & 30 \\
7 & 1.00 & 8.2 & 385 & 249 & 2.9 & 5.5 & 108 & 29 \\
8 & 1.50 & 8.0 & 373 & 143 & 3.0 & 6.9 & 106 & 26 \\
$9^{\mathrm{b}}$ & $\mathrm{VCl}_{2}\left(\mathrm{salenCl}_{2}\right)$ & 1.00 & 2.6 & 130 & 382 & 2.0 & 4.0 & 125 & 33 \\
$10^{\mathrm{c}}$ & & 1.00 & 3.7 & 18 & 477 & 2.0 & 4.3 & 130 & 39 \\
$11^{\mathrm{b}}$ & $\mathrm{Cp}_{2} \mathrm{VCl}_{2}$ & 1.00 & 0.8 & 40 & 290 & 2.4 & 4.3 & 110 & 25 \\
$12^{\mathrm{c}}$ & & 1.00 & 1.0 & 5 & 394 & 2.5 & 4.8 & 112 & 30 \\
\hline
\end{tabular}

Standard deviation does not exceed $7 \%$ for yield, $0.04 \%$ for $M_{w}$ and $M_{w} / M_{n}$, and $1 \%$ for $T_{m}$ and $X$

Copolymerization conditions: catalyst system $=0.300 \mathrm{~g}$, temperature $=30{ }^{\circ} \mathrm{C}$, ethylene pressure $=0.5 \mathrm{MPa}$, time $=30 \mathrm{~min}$., solvent-hexane $=150 \mathrm{~mL}$, activator- $\mathrm{AlEt}_{2} \mathrm{Cl}=3.0 \times 10^{-3} \mathrm{~mol}_{\text {, }}$ ethyl trichloroacetate-ETA $=1.0 \times 10^{-3} \mathrm{~mol}$

a $\mathrm{X}$-Crystallinity degree determined by DSC

${ }^{\mathrm{b}}$ Catalyst $=2.0 \times 10^{-6} \mathrm{~mol}$

${ }^{c}$ Catalyst $=2.0 \times 10^{-5} \mathrm{~mol}$

(Fig. 1S). For the studied SIL systems, $M_{\mathrm{w}}$ of copolymer is generally lower than that of polyethylene. The $\mathrm{VCl}_{2}\left(\right.$ salenCl$\left._{2}\right)$ catalyst, both as the SIL and homogeneous system, produces the copolymers with slightly higher $M_{\mathrm{w}}$ than the $\mathrm{Cp}_{2} \mathrm{VCl}_{2}$ analogue.

A correlation of copolymer $M_{\mathrm{w}}$ and microstructure can be seen. At low initial NB concentration, there are isolated NB units in the copolymer chain, which results in typical decrease of $M_{\mathrm{w}}$ as compared to polyethylene [7-9]. Increase of the NB concentration causes appearance of a small alternating, syndiotactic or isotactic copolymer blocks, which results in an increase of molecular weight. Higher initial $\mathrm{NB}$ concentration (1.0 and $1.5 \mathrm{~mol} / \mathrm{L})$ results in more than $24 \mathrm{~mol} \% \mathrm{NB}$ incorporation. Diads and longer microblocks appear, which correlate with $M_{\mathrm{w}}$ decreases and $M_{\mathrm{w}} / M_{\mathrm{n}}$ broadening ( $\left.>2.0\right)$.

The selected DSC thermograms of E/NB copolymers obtained using SIL/ $\mathrm{Cp}_{2} \mathrm{VCl}_{2}$ are presented in Fig. 6. As can be seen, the copolymer samples reveal single broad melting peaks. In contrast to polyethylene obtained in similar conditions (Fig. 6a), the copolymers are characterized by lower melting temperature as well as crystallinity degree. With increase of NB incorporation, a decrease of melting temperature and crystallinity values is observed (Fig. 6b, c). This can be 
related to incorporation of bulky NB units in the polymer chain, which leads to disorder of molecular structure [13].

The constant ethylene concentration in the copolymerization time, obtained by control of its pressure, and change of the NB concentration caused by its incorporation in the growing polymer influence its composition. DSC thermograms of the copolymers show a decrease of melting temperature and crystallinity degree with reaction time (Fig. 6d, e). The ${ }^{13} \mathrm{C}$ NMR spectra show appearance of triads, which were absent at the beginning of polymerization (Fig. 2S). For copolymer samples obtained using homogeneous catalyst, decrease of melting temperature and crystallinity degree takes place much faster (Fig. 6f, g). The ${ }^{13} \mathrm{C}$ NMR spectra show alternating E/NB sequences at the beginning of the copolymerization, but diads and triads can be seen with time (Fig. 3S).

Morphology of E/NB copolymers also depends on the amount of NB incorporation. SEM images (Fig. 2c, d) of the copolymer sample with rather low NB incorporation ( $7 \mathrm{~mol} \%$ ) show that copolymer looses its fibrous feature, characteristic for polyethylene obtained on the same catalyst [32]. In addition, the irregular shape indicates that catalyst replication does not take place. Further increase of NB incorporation makes the copolymer samples transparent.

\section{Copolymerization of ethylene with 1-octene}

Ethylene/1-octene copolymerization was performed using the same SIL systems with $\mathrm{Cp}_{2} \mathrm{VCl}_{2}$ or $\mathrm{VCl}_{2}\left(\mathrm{salenCl}_{2}\right)$ and, for comparison, the non-supported analogues (Table 2). In general, activity of the studied catalysts in E/Oct copolymerization is lower as compared to E/NB reaction. At initial 1-octene concentration $0.5 \mathrm{~mol} / \mathrm{L}$, a better performance shows the SIL/ $\mathrm{VCl}_{2}\left(\mathrm{salenCl}_{2}\right)$ system, but at higher comonomer concentration, a better stability shows the SIL/Cp $\mathrm{V}_{2} \mathrm{VCl}_{2}$ catalyst (Table 2, items 1,4 and 2,7).

Moreover, the activities of the studied SIL catalysts are higher than those for homogeneous analogues, at the same catalyst concentration as well as tenfold increase (Table 2, items 2, 9,10 and 7, 11, 12). This also confirms that catalyst concentration does not influence considerable on comonomer incorporation [36]. However, a better incorporation is ensured by the SIL catalysts.

The influence of 1-octene concentration on its incorporation as well as the catalyst activity is shown for more stable $\mathrm{SIL} / \mathrm{Cp}_{2} \mathrm{VCl}_{2}$ system (Fig. 3c). As in case of $\mathrm{E} / \mathrm{NB}$ copolymerization, activity increases with increase of the initial 1-octene concentration, up to maximum at $0.9 \mathrm{~mol} / \mathrm{L}$. At higher comonomer concentration, the activity decreases, but decline is lower than for the E/NB copolymerization. 1-Octene incorporation increases linearly with initial concentration, similarly to E/NB copolymers, but it is much lower, in the range of 3.9-6.9 mol\%. It should be noted that comonomer incorporation obtained using the studied SIL systems is much higher than in case of E/Oct copolymers produced using typical heterogeneous post-metallocene vanadium catalyst with salen-type ligand anchored on magnesium support, where at comparable 1-octene, concentration in feed incorporation does not exceed $1 \mathrm{~mol} \%$ [28]. 


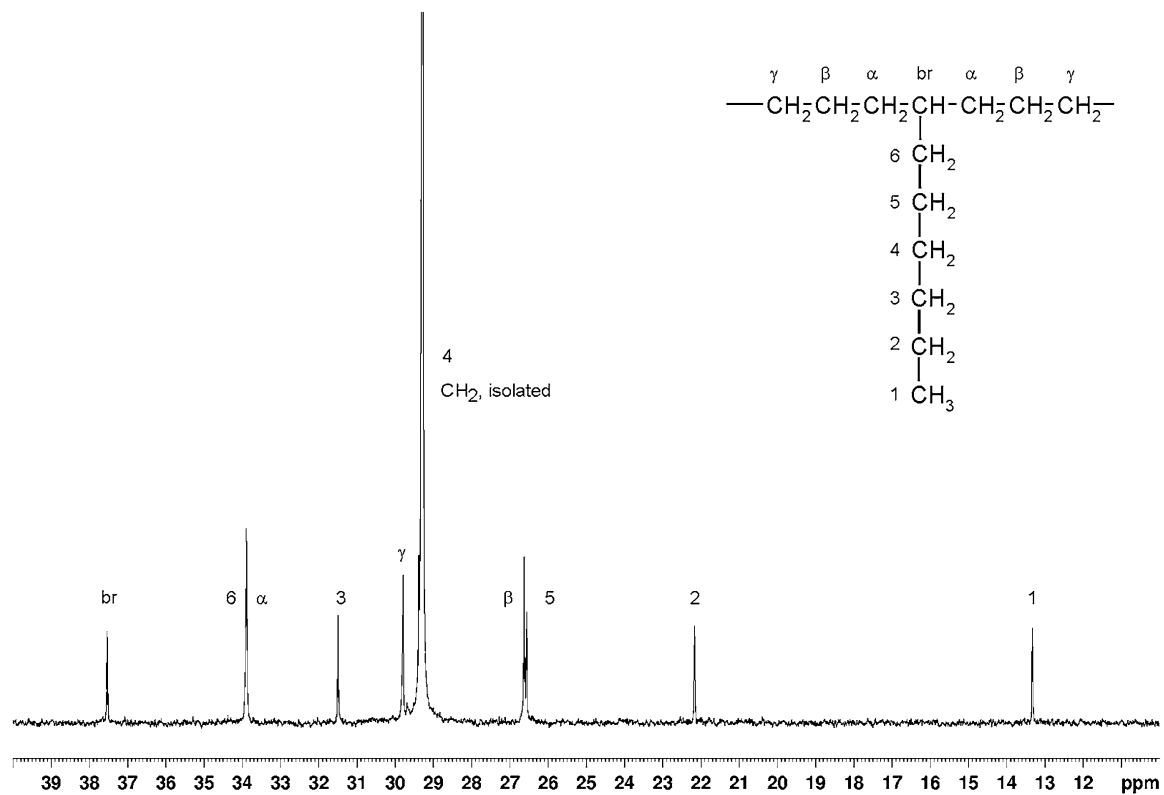

Fig. 7 Selected ${ }^{13} \mathrm{C}$ NMR spectrum of ethylene/1-octene copolymer obtained using the studied SIL system (Table 2, item 8)

As in case of $\mathrm{E} / \mathrm{NB}$ copolymerization, kinetics profile performed using the $\mathrm{Cp}_{2} \mathrm{VCl}_{2}$ catalyst confirms higher stability of the $\mathrm{SIL}$ system as compared to homogeneous analogue (Fig. 5c, d).

The ${ }^{13} \mathrm{C}$ NMR spectrum of E/Oct copolymer (Fig. 7) containing $6.9 \mathrm{~mol} \%$ comonomer is typical for this copolymer with low 1-octene incorporation [34]. Considering possible microstructure of ethylene $(\mathrm{E})$ and octene $(\mathrm{O})$ units [39], the signals can be attributed to $\mathrm{CH}_{3}(1)(13.34 \mathrm{ppm}, \mathrm{EOE}+\mathrm{OOE}+\mathrm{EOO}+\mathrm{OOO})$, $\mathrm{CH}_{2}(2)$ (22.18 ppm, $\left.\mathrm{EOE}+\mathrm{OOE}+\mathrm{EOO}+\mathrm{OOO}\right)$, and $\beta-\mathrm{CH}_{2}$ (26.58 ppm, $\mathrm{OEE}), \mathrm{CH}_{2}(5)$ (26.60 ppm, $\left.\mathrm{EOE}+\mathrm{OOE}+\mathrm{EOO}+\mathrm{OOO}\right), \mathrm{CH}_{2}(4)$ and $\mathrm{CH}_{2}$ (isol(EEEE) (29.30 ppm), $\gamma-\mathrm{CH}_{2}$ (29.80 ppm, OEEE), $\mathrm{CH}_{2}(3)$ (31.50 ppm, $\mathrm{EOE}+\mathrm{OOE}+\mathrm{EOO}+\mathrm{OOO}), \mathrm{CH}_{2}(6), \alpha-\mathrm{CH}_{2}(33.90 \mathrm{ppm}, \mathrm{EOEE}+\mathrm{EOE}$, and $\mathrm{CH}$ (bridge) (37.54 ppm, EOE). As can be seen, the lack of signals from 40 to $42 \mathrm{ppm}$ and $25 \mathrm{ppm}$ indicates that there is no blocks and alternate-type sequence. Therefore, the analyzed E/Oct copolymer contains only the EOE and EEE sequences, thus 1-octene units are isolated by ethylene units in the polymer chains.

The properties of E/Oct copolymer also depend on the comonomer incorporation. The molecular weight of E/Oct copolymers obtained using the SIL systems is lower than the molecular weight of polyethylene as well as the E/NB copolymers. Increase of the 1-octene incorporation decreases molecular weight, but broadens monomodal molecular-weight distribution (Table 2, Fig. $1 \mathrm{~S}$ c,d). Slightly broader $M_{w} / M_{n}$ as compared to the E/NB copolymers is also known from the literature and can be attributed to character of comonomer [36, 40]. 
It should be noted that the studied SIL/ $/ \mathrm{VCl}_{2}\left(\mathrm{salenCl}_{2}\right)$ catalyst produces copolymer with much narrower $M_{\mathrm{w}} / M_{\mathrm{n}}$ as compared to the same $\mathrm{VCl}_{2}\left(\mathrm{salenCl}_{2}\right)$ catalyst directly anchored on magnesium support, where copolymer $M_{\mathrm{w}} / M_{\mathrm{n}}$ value was in the range from 35 up to even 70 [28]. This proves that in the presented SIL systems, the solid support does not interact directly with the catalyst, through creation of various active sites, which has influence on the properties of the obtained copolymer.

Figure $6 \mathrm{~h}-\mathrm{k}$ shows selected DSC thermograms of copolymers obtained using $\mathrm{SIL} / \mathrm{Cp}_{2} \mathrm{VCl}_{2}$. As can be seen, all thermograms show single melting peaks, which broaden with increase of 1-octene incorporation. The melting temperature and crystallinity degree decrease with increase of commoner incorporation (Fig. 6h, i), and their values are lower in comparison with those for pure polyethylene.

Differences in decrease of the melting temperature and crystallinity degree with copolymerization time (Fig. 6j, k) indicate a composition drift. However, the changes are smaller than in case of E/NB copolymers, which can be attributed to lower incorporation of the 1-octene comonomer. In addition, the ${ }^{13} \mathrm{C} N \mathrm{NR}$ spectra shows that copolymer microstructure is not changed, and only isolated 1-octene units are observed (Fig. 4S). SEM images (Fig. 2e, f) show that 1-octene incorporation results in irregular copolymer with porous surface.

\section{Conclusions}

In the presented study, supported ionic liquid (SIL) catalysts are used for the first time in copolymerization reaction. Two vanadium catalysts, metallocene and postmetallocene, are investigated in copolymerization of ethylene with two most important comonomers, norbornene and 1-octene. The studied SIL catalysts show that comonomer unit can be efficiently incorporated in the growing polymer chain when the catalyst active centers are placed in the ionic liquid medium. The studied SIL catalysts reveal higher activities and better comonomer incorporation than analogous non-supported catalysts. In addition, the applied systems enable a better norbornene and 1-octene incorporation than heterogeneous catalysts described in the literature. Copolymer properties depend on the kind of catalyst as well as the kind and amount of incorporated comonomer. The characteristic feature is narrow molecular-weight distribution, which results from application not only vanadium metal center, but also ionic liquid medium, which provides single active sites. The presented study opens the way for investigation of copolymerization using various types of the SIL catalysts, including different transition metals as well as types of comonomers.

Open Access This article is distributed under the terms of the Creative Commons Attribution 4.0 International License (http://creativecommons.org/licenses/by/4.0/), which permits unrestricted use, distribution, and reproduction in any medium, provided you give appropriate credit to the original author(s) and the source, provide a link to the Creative Commons license, and indicate if changes were made. 


\section{References}

1. Tritto I, Boggioni L, Ferro Dino R (2006) Metallocene catalyzed ethene- and propene co-norbornene polymerization: Mechanisms from a detailed microstructural analysis. Coord Chem Rev 250:212-241. doi:10.1016/j.ccr.2005.06.019

2. Blank F, Janiak C (2009) Metal catalysts for the vinyl/addition polymerization of norbornene. Coord Chem Rev 253:827-861. doi:10.1016/j.ccr.2008.05.010

3. Tschage M, Jung S, Spaniol TP, Okuda J (2015) Polymerization of norbornene using chiral bis(phenolate) zirconium catalysts. Macromol Rapid Commun 36:219-223. doi:10.1002/marc. 201400386

4. Xu G, Narayana GV, Speiser M, Wang D, Zou Y, Buchmeiser MR (2014) Poly(ethylene)-copoly(norborn-2-ene) prepared by group IV bisamido and half-sandwich amido complexes with pendant aminoborane groups: vinyl insertion vs ring-opening metathesis polymerization. Macromol Chem Phys 215:893-899. doi:10.1002/macp.201400032

5. Zhang W, Wang Y, Redshaw C, Hao X, Sun WH (2012) 2-Aldiminophenoxytitanium chloride complexes: Synthesis, characterization, and ethylene (co-)polymerization behavior. J Organomet Chem 715:119-128. doi:10.1016/j.jorganchem.2012.05.048

6. Wu JQ, Pan L, Li YG, Liu SR, Li YS (2009) Synthesis, structural characterization, and olefin polymerization behavior of vanadium(III) complexes bearing tridentate Schiff base ligands. Organometallics 28:1817-1825. doi:10.1021/om801028g

7. Wu JQ, Mu JS, Zhang SW, Li YS (2010) Vanadium(V) complexes containing tetradentate amine trihydroxy ligands as catalysts for copolymerization of cyclic olefins. J Polym Sci Part A: Polym Chem 48:1122-1132. doi:10.1002/pola.23868

8. Wang JB, Lu LP, Liu JY, Li JS (2014) [ONN]-type amine pyridine(s) phenolate-based oxovana$\operatorname{dium}(\mathrm{V})$ catalysts for ethylene homo- and copolymerization. Dalton Trans 43:2926-12934. doi:10. 1039/C4DT01166J

9. Wang JB, Lu LP, Liu JY, Mu HI, Li YS (2015) [ONNO]-type oxovanadium(V) complexes containing amine pyridine bis(phenolate) ligands: synthesis, characterization and catalytic behavior for ethylene (co)polymerization. J Mol Catal A Chem 398:289-296. doi:10.1016/j.molcata.2014.12.016

10. Diteepeng N, Tang X, Hou X, Phomphrai K, Nomura K (2015) Ethylene polymerisation and ethylene/norbornene copolymerisation by using aryloxo-modified vanadium(V) complexes containing 2,6-difluoro-, dichloro-phenylimido complexes. Dalton Trans 44:12273-12281. doi:10.1039/ C4DT04026K

11. Wendt RA, Fink G (2001) ${ }^{13} \mathrm{C}$ NMR studies of ethene/norbornene copolymers using ${ }^{13} \mathrm{C}$-enriched monomers: signal assignments of copolymers containing norbornene microblocks of up to a length of three norbornene units. Macromol Chem Phys 202:3490-3501. doi:10.1002/15213935(20011201)202:18<3490:AID-MACP3490>3.0.CO;2-6

12. Wendt RA, Fink G (2003) Ethene-norbornene copolymerizations using two different homogeneous metallocene catalyst systems and investigations of the copolymer microstructure. J Mol Catal A Chem 203:101-111. doi:10.1016/S1381-1169(03)00371-6

13. Manteghi A, Arabi H, Jahani Y (2015) Synthesis, characterization, rheological and thermal behavior of metallocene ethylene-norbornene copolymers with low norbornene content using pentafluorophenol modified methylaluminoxane. Polym Int 64:900-906. doi:10.1002/pi.4863

14. Tritto I, Marestin C, Boggioni L, Sacchi MC, Brintzinger HH, Ferro DR (2001) Stereoregular and stereoirregular alternating ethylene-norbornene copolymers. Macromolecules 34:5770-5777. doi:10. $1021 / \mathrm{ma0} 10122 \mathrm{r}$

15. Tritto I, Boggioni L, Ravasio A, Zampa C, Hitzbleck J, Okuda J, Bredeau S, Dubois P (2007) Ethylene-norbornene copolymerization by rare-earth metal complexes and by carbon nanotubesupported metallocene catalysis. Macromol Symp 260:114-121. doi:10.1002/masy.200751416

16. Goretzki R, Fink G (1999) Homogeneous and heterogeneous metallocene/MAO-catalyzed polymerization of functionalized olefins. Macroml Chem Phys 200:881-886. doi:10.1002/(SICI)15213935(19990401)200:4<881:AID-MACP881>3.0.CO;2-N

17. Jang YJ, Nenov N, Klapper M, Müllen K (2003) Organic nanoparticles with polypropyleneoxide chains as support for metallocene catalysts: ethylene homopolymerization and ethylene/ $\alpha$-olefin copolymerization. Polym Bull 50:343-350. doi:10.1007/s00289-003-0183-7

18. Baier MC, Zuideveld MA, Mecking S (2014) Post-metallocenes in the industrial production of polyolefins. Angew Chem Int Ed 53:9722-9744. doi:10.1002/anie.201400799 (Epub 2014 Aug 21) 
19. Cossoul E, Baverel L, Martigny E, Macko T, Boisson C, Boyron O (2013) Homogeneous copolymers of ethylene with $\alpha$-olefins synthesized with metallocene catalysts and their use as standards for TREF calibration. Macromol Symp 330:42-52. doi:10.1002/masy.201300022

20. Lee JS, Ko YS (2014) Control of the molecular structure of ethylene-1-hexene copolymer by surface functionalization of SBA-15 with different compositions of amine groups. J Mol Catal A: Chem 386:120-125. doi:10.1016/j.molcata.2014.01.015

21. Zhao N, Cheng R, He X, Liu Z, Liu B (2014) A novel $\mathrm{SiO}_{2}$-supported $\mathrm{Cr}-\mathrm{V}$ bimetallic catalyst making polyethylene and ethylene/1-hexene copolymers with bimodal 10.1002/macp.201400094

22. Ndiripo A, Joubert D, Pasch H (2016) Ethylene/1-heptene copolymers as interesting alternatives to 1-octene-based LLDPE: Molecular structure and physical properties. J Polym Sci, Part A: Polym Chem 54:962-975. doi:10.1002/pola.27932

23. Chatterjee T, Dey P, Nando GB, Naskar K (2015) Thermo-responsive shape memory polymer blends based on alpha olefin and ethylene propylene diene rubber. Polymer 78:180-192. doi:10.1016/j. polymer.2015.10.007

24. Shamiri A, Chakrabarti MH, Jahan S, Hussain MA, Kaminsky W, Aravind PV, Yehye WA (2014) The influence of Ziegler-Natta and metallocene catalysts on polyolefin structure, properties, and processing ability. Materials 7:5069-5108. doi:10.3390/ma7075069

25. Wu CJ, Nayab S, Woo HY, Hahn JS, Lee HS, Kang SO, Lee H (2014) Synthesis and X-ray crystal structure of $\left[\mathrm{Me}_{2} \mathrm{Si}\left(\mathrm{C}_{5} \mathrm{Me}_{2} \mathrm{H}_{2}\right)\left({ }^{t} \mathrm{BuN}\right)\right] \mathrm{MCl}_{2}(\mathrm{M}=\mathrm{Ti}, \mathrm{Zr})$ bearing a 3,4-dimethylcyclopentadienyl ring: Investigation of the substitution effect on the cyclopentadienyl $(\mathrm{Cp})$ ring for catalytic performance in ethylene/1-octene (co)polymerization. Polyhedron 67:199-204. doi:10.1016/j.poly.2013. 08.072

26. Golisz SR, Bercaw JE (2009) Synthesis of early transition metal bisphenolate complexes and their use as olefin polymerization catalysts. Macromolecules 42:8751-8762. doi:10.1021/ma901659q

27. Ketloy C, Jongsomjit B, Praserthdam P (2007) Characteristics and catalytic properties of [t$\left.\mathrm{BuNSiMe}_{2} \mathrm{Flu}\right] \mathrm{TiMe}_{2} / \mathrm{dMMAO}$ catalyst dispersed on various supports towards ethylene/1-octene copolymerization. Appl Catal A Gen 327:270-277. doi:10.1016/j.apcata.2007.05.025

28. Białek M, Czaja K, Pietruszka A (2013) Ethylene/1-olefin copolymerization behaviour of vanadium and titanium complexes bearing salen-type ligand. Polym Bull 70:1499-1517. doi:10.1007/s00289012-0903-y

29. Selvam T, Machoke A, Schwieger W (2012) Supported ionic liquids on non-porous and porous inorganic materials-A topical review. Appl Catal A Gen 445-446:92-101. doi:10.1016/j.apcata.2012. 08.007

30. Van Doorslaer C, Wahlen J, Mertens P, Binnemans K, de Vos D (2010) Immobilization of molecular catalysts in supported ionic liquid phases. Dalton Trans 39:8377-8390. doi:10.1039/c001285h

31. Ochędzan-Siodłak W, Dziubek K (2014) Metallocenes and post-metallocenes immobilized on ionic liquid-modified silica as catalysts for polymerization of ethylene. Appl Catal A Gen 484:134-141. doi:10.1016/j.apcata.2014.07.016

32. Ochędzan-Siodłak W, Bihun A (2015) Direct synthesis of fibrous high molecular weight polyethylene using vanadium catalysts supported on an $\mathrm{SiO}_{2}$ ionic liquid system. Polym Int 64:1600-1606. doi:10.1002/pi.4958

33. Ochędzan-Siodłak W, Bihun A, Olszowy A, Rajfur M, Jesionowski T, Siwińska-Stefańska K (2016) Ethylene polymerization using vanadium catalyst supported on silica modified by pyridinium ionic liquid. Polym Int 65:1089-1097. doi:10.1002/pi.5160

34. Malaika SA, Peng X, Watson H (2006) Metallocene ethylene-1-octene copolymers: Influence of comonomer content on thermo-mechanical, rheological, and thermo-oxidative behaviours before and after melt processing in an internal mixer. Polym Degrad Stab 91:3131-3148. doi:10.1016/j. polymdegradstab.2006.07.020

35. Zhuravlev LT (2000) The surface chemistry of amorphous silica. Zhuravlev model. Colloids Surf Phys Eng Aspects 173:1-38. doi:10.1016/S0927-7757(00)00556-2

36. Tang L-M, Wu J-Q, Duan Y-Q, Pan L, Li Y-G, Li Y-S (2008) Ethylene polymerizations, and the copolymerizations of ethylene with hexene or norbornene with highly active mono( $\beta$-enaminoketonato) vanadium(III) catalysts. J Polym Sci Part A Polym Chem 46:2038-2048. doi:10.1002/pola. 22538

37. Li X, Hou Z (2008) Organometallic catalysts for copolymerization of cyclic olefins. Coord Chem Rev 252:1842-1869. doi:10.1016/j.ccr.2007.11.027 
38. Leone G, Pierro I, Zanchin G, Forni Bertini F, Rapallo A, Ricci G (2016) Vanadium (III)-catalyzed copolymerization of ethylene with norbornene: Microstructure at tetrad level and reactivity ratios. J Mol Catal A Chem 424:220-231. doi:10.1016/j.molcata.2016.09.002

39. Kong Y, Yi J, Dou X, Liu W, Huang Q, Gao K, Yang W (2010) With different structure ligands heterogeneous Ziegler-Natta catalysts for the preparation of copolymer of ethylene and 1-octene with high comonomer incorporation. Polymer 51:3859-3866. doi:10.1016/j.polymer.2010.06.032

40. Wang W, Nomura K (2005) Remarkable effects of aluminum cocatalyst and comonomer in ethylene copolymerizations catalyzed by (arylimido)(aryloxo)vanadium complexes: efficient synthesis of high molecular weight ethylene/norbornene copolymer. Macromolecules 38:5905-5913. doi:10.1021/ $\mathrm{ma050629s}$ 